\title{
Constraints on semantic priming in reading: A fixation time analysis
}

\author{
PATRICK CARROLL \\ University of Massachusetts, Amherst, Massachusetts
}

and

MARIA L. SLOWIACZEK

University of Texas at Austin, Austin, Texas

\begin{abstract}
In Experiment 1, subjects read sentences containing a category name or a neutral prime that was followed by a target exemplar that varied in typicality. Fixation time on the target exemplar was the measure of processing difficulty. The category name facilitated processing for both high- and low-typicality exemplars. Unexpectedly, high-typicality exemplars were processed more quickly than low-typicality exemplars in both primed and unprimed conditions. Experiment 2 extended the priming effect to primary associates. Most importantly, the priming effect was influenced by the syntactic structure of the stimulus sentence. When both the prime and the associated target word were in the same clause, semantic priming occurred, but when the prime and target were in different clauses, no associative facilitation was observed. These results were interpreted as supporting a clausal processing hypothesis based on an autonomous modular view of the language processing system. Furthermore, the results were consistent with direct control models of eye movements, which claim that fixation duration reflects the timing of processing related to the word currently under fixation.
\end{abstract}

Skilled reading requires the integration of many kinds of information as words, sentences, and paragraphs are built into a mental representation of the discourse. Although context undoubtedly influences the integration of newly encountered information, the effects of different kinds of context are not yet well understood. The most restricted kind of semantic context is that contained within a phrase, frequently within a word pair. For example, in a noun phrase, a modifier might strongly suggest what the following noun will be (e.g., "amusement park" or "Goodyear blimp"). A second kind of context is provided by other information in the sentence. Sentential context includes semantic information from other phrases and clauses within the sentence as well as grammatical constraints (subcategorizations, frames, thematic roles, etc.). The most global level of context is provided by the theme or topic of the paragraph or passage. This type of context is built up over several sentences and its effects will presumably persist until the topic is changed or the discourse is terminated.

This research was conducted in partial fulfillment of the requirements of the $\mathrm{PhD}$ at the University of Massachusetts, Amherst, by the first author. It was supported by National Institute of Child Health Grants HD12727 and HD17246 (principal investigator, Keith Rayner). We thank Keith Rayner, Lyn Frazier, Sandy Pollatsek, Chuck Clifton, and Dan Anderson for their comments and support. We would especially like to thank Jim Chumbley for his help and guidance throughout this research. Requests for reprints should be sent to Patrick Carroll, Department of Psychology, Bronfman Science Center, Williams College, Williamstown, MA 01267
The effect of a single-word context on the processing of another word has been extensively reported in the semantic priming literature (Antos, 1979; Becker, 1979, 1980; de Groot, 1983; de Groot, Thomassen, \& Hudson, 1982; den Heyer, Briand, \& Dannenbring, 1983; den Heyer, Briand, \& Smith, 1985; Fischler, 1977a, 1977b; Meyer \& Schvaneveldt, 1971). For example, Schvaneveldt and Meyer (1973) demonstrated that prior presentation of a word facilitates lexical decisions about a strong associate (e.g., bread-butter), even when there is an unassociated word (e.g., star) intervening (but see Gough, Alford, \& Holley-Wilcox, 1981). Priming effects also persist across temporal delays between the prime and target word, although the pattern of facilitation and inhibition changes (Lorch, 1982; Neely, 1976, 1977). At short delays, there is automatic facilitation of associated words without inhibition for unexpected items. At longer delays, the priming effects appear to be maintained by conscious effort, perhaps a guessing strategy, that is characterized by inhibition for unexpected lexical items and by facilitation of associated words.

Experimental demonstrations of sentential context effects have been available for more than 20 years (Morton, 1964; Tulving \& Gold, 1963; Tulving, Mandler, \& Baumal, 1964). More recent studies using word naming latency and lexical decision tasks have generally been consistent with these early findings. Lexical decision (Kleiman, 1980; Schuberth \& Eimas, 1977) and pronunciation time (Stanovich \& West, 1979) are slower on a word that completes a sentence if it is incongruous with the sen- 
tence frame, and lexical decision is faster if the word is predictable (Fischler \& Bloom, 1979) when compared with congruous but less predictable sentence completions. Semantically anomalous sentence completions lead to inhibition in the lexical decision task, presumably reflecting increased processing demands (Fischler \& Bloom, 1980, 1985; Schwanenflugel \& Shoben, 1985).

These experiments make it clear that the information provided by a single sentence can influence word processing. However, they do not necessarily show that sentence context is used in normal sentence processing. In this paradigm, the sentence frame is presented prior to the target word, and the onset of the primed target is delayed. This does not mimic the time course of normal reading, which lacks such a delay. Various techniques have been developed to reduce this problem and to make the experimental task more like normal reading. For instance, in a self-paced reading task, time to report comprehension of critical sentences in multisentential passages is measured. Using this task, facilitation effects were found for class-inclusion relationships between words in the passage (Garnham, 1981; Garrod \& Sanford, 1977). Reading times were faster on a target sentence if it contained an exemplar (e.g., bus) of a category (e.g., VEHICLE) that had been introduced earlier in the passage than if the later sentence contained the category name and the earlier sentence contained the exemplar. Although this paradigm allows the subject to read more naturally, it does not provide specific data about what part of the sentence is being processed when the facilitation effects appear.

\section{Context Effects in Eye Tracking}

With the development of eye-tracking techniques, it is now possible to monitor reading time on-line without introducing disruptive secondary tasks. Evidence that the perceptual span is restricted to a region of only one or two words in extent (McConkie \& Rayner, 1975; McConkie, Zola, Blanchard, \& Wolverton, 1982; Rayner, Inhoff, Morrison, Slowiaczek, \& Bertera, 1981; Rayner, Well, Pollatsek, \& Bertera, 1982) and that linguistically useful visual information is not available during saccades (Matin, 1974; Volkmann, 1962) supports the assumption that information about the location and duration of individual fixations can be used to make inferences about processing of specific areas of the text and of individual words.

A substantial body of recent work suggests that the mental processes used in reading comprehension are reflected in eye fixations. Readers fixate longer on less frequent words (Just \& Carpenter, 1980; Rayner, 1977) and on words that are unlikely in a particular passage (S. F. Ehrlich \& Rayner, 1981). Fixation times increase when a passage is unusual (Inhoff, 1984; Inhoff, Lima, \& Carroll, 1984) or if sentence structures are misparsed (Frazier \& Rayner, 1982). Other studies suggest that fixation durations are affected by the difficulty of making inferences about (Just \& Carpenter, 1978) and connections to (K. Ehrlich \& Rayner, 1983; Vonk, 1984) related concepts that are presented earlier in the text. These studies have encouraged the point of view that eye fixations are invariably a direct reflection of processing difficulty in reading. According to this view, the words that are currently within the perceptual span are the words that are being processed at the linguistic level, and the eye stays fixated on that area until these words are completely integrated into the discourse representation. Thus, the fixation location reveals what word is being processed, and the fixation duration reflects the full set of comprehension and integration processes initiated by the addition of the fixated word.

Closer scrutiny of the literature suggests that this viewpoint has only weak support from empirical studies. Many experiments that report effects of reading comprehension on immediate fixation durations manipulate the texts so that inappropriate words or garden path sentences are introduced. Indeed, there are few published studies of semantic effects on individual fixation times that cannot be explained by surprise, by anomaly, or by an unnatural reading task. In most cases, longer fixation durations occur when the reader has made the wrong interpretation of a word so that the word does not fit with the previous content of the passage (Carpenter \& Daneman, 1981; K. Ehrlich \& Rayner, 1983). Other studies force the reader into a highly attentive reading strategy by presenting complex and unusual words (Carpenter \& Just, 1981; Inhoff, 1984) or by introducing anomalies in other sentences that may alert the reader to be more careful (Frazier \& Rayner, 1982). Zola (1984) tested whether or not the meaning of a preceding adjective would affect fixation time on a noun, and the effects of expectations on fixation duration were small, but significant. Balota, Pollatsek, and Rayner (1985) found evidence of semantic priming that influenced both processing immediately prior to viewing the primed item and processing time on the primed word. However, even these experiments must be viewed with caution. Zola used a stimulus set that included misspelled items, and Balota et al. made display changes in the critical region. Both of these procedures, although useful and informative about normal reading, may induce unusual attentiveness to detail by the reader.

What happens when the surprise is not big enough or when the reader is not forced to read with excessive caution? The demonstration that context can influence fixation times only confirms that such effects are possible under specific conditions, not that these effects appear regularly in normal reading. Further experiments are needed to show that semantic processes affect eyemovement behavior of people reading sentences that have no surprise or anomaly.

In Experiment 1, we tested semantic priming effects by monitoring eye movements during normal reading. By using the eye-movement technique, we were able to see whether the association from a category name can facilitate processing of a category member within the constraints of reading a sentence. In addition, we were able to look for the effect of the preceding context as soon as the word was encountered in the text (i.e., when it was 
fixated). If eye movements are controlled by the completion of the cognitive processes required to integrate each word with the previous text, we expect the fixation time on the target word to reflect the difficulty of this process.

Our predictions are based on one plausible account of the priming phenomenon: the spreading activation model of semantic memory. According to this model, the effects of priming are determined by the stored representation of word-related concepts in semantic memory. Furthermore, we studied how priming effects are maintained during sentence processing by varying the amount of material between the category prime and the primed exemplar.

\section{Language Processing Theories}

Language processing theories differ in the extent to which they propose constraints on how prior context can affect processing of new information. Interactive models (Just \& Carpenter, 1980; Marslen-Wilson \& Welsh, 1978; Rumelhart \& McClelland, 1982; Sanocki et al., 1985) suggest that there is a great deal of influence of processing "levels" or "stages" on one another. Information from previously read sentences, phrases, and words is regularly available to ease and direct the processing of new words and phrases. Since these models usually create a broad range of interactive influences, they assume that each word is completely integrated into the mental representation of the discourse as soon as it is encountered.

By contrast, modular processing models (Forster, 1979; Frazier, Clifton, \& Randall, 1983; Freeman \& Forster, 1985) place constraints on how context can affect processing and when information can be integrated into a text representation. Of particular interest are theories that claim that syntactic structures guide and constrain the flow of processing (Bever \& Hurtig, 1975; J. A. Fodor, Bever, \& Garrett, 1974).

In Experiment 2, we tested whether or not the semantic facilitation effect was constrained by the structure of the sentence. If the language processing system performs semantic analysis on subunits of the sentence determined by the syntactic structure, all context information may not be immediately available to facilitate word processing. This prediction is in direct contrast with the predictions of the spreading activation model, which suggests that facilitation is independent of later structuring processes. Experiment 2 provides a test of these models.

\section{EXPERIMENT 1}

One important version of the priming phenomenon is the typicality effect. Typicality is a measure of how well an exemplar fits the prototype of a category (Rosch, 1973). Typicality is a relative property of a word in the context of the category, not an invariant quality of the word. Semantic priming experiments have shown greater facilitation effects for highly typical exemplars by the appropriate category name than for less typical exemplars (Rosch, 1975).
Priming and typicality, manipulated in Experiment 1, can be interpreted within a spreading activation framework, with typicality represented as a function of distance or strength in a semantic network (Collins \& Loftus, 1975; Loftus, 1975). Four aspects of this framework lead to predictions about Experiment 1. First, the cegree of activation of a concept is determined by the degree of relatedness of a word to the prime. The more closely two words are associated, the greater the facilitative effect of activation of one word on processing the other. Therefore, high-typicality exemplars should be processed more quickly than low-typicality exemplars. Second, in the absence of specific semantic information, word encoding time is determined by other factors, such as word length and frequency. The high- and low-typicality exemplars were controlled for length and frequency in this experiment, so there should be no difference in processing time when the prime is not presented. Third, semantic memory activation influences word encoding rather than the integration of the word with the sentence or discourse. Typicality effects should be determined by the relationship between the prime and target, and not by other aspects of the sentence form.

The final prediction from the spreading activation model is that activation of a concept is assumed to arise quickly and to dissipate over time unless reactivation occurs (Collins \& Loftus, 1975). In the present experiment, the relative priming interval was manipulated, by varying the amount of material to be read between the prime and exemplar. If activation dissipates over delay and intervening material, the extra material should reduce the size of the priming and typicality effects. In the unprimed condition, the delay should have no effect, since no category priming would have taken place.

\section{Method}

Subjects. Sixteen members of the University of Massachusetts community were paid to participate in the experiment. All subjects had normal uncorrected vision. Approximately half had never participated in an eye-movement experiment before.

Apparatus. Eye movements were recorded by a Stanford Research Institute Dual Purkinje Eyetracker (Cornsweet \& Crane, 1973) which was interfaced with a Hewlett Packard 2100 computer. The eyetracker has a tested accuracy of less than $.25^{\circ}$ of visual angle, and the output is linear over the visual angle of the sentences (less than $14^{\circ}$ ). Horizontal and vertical coordinates of the position of the right eye were sampled every millisecond. Saccades and fixations were determined in real time by averaging the horizontal position over each 4-msec sequence of samples and comparing this to the previous $4 \mathrm{msec}$.

Stimuli were presented on a Hewlett Packard 1300A Cathode Ray Tube (CRT) in standard lowercase format. The luminance was adjusted to a comfortable level for each subject. Each letter was composed of dots from a $5 \times 7$ matrix. The subject was positioned $46 \mathrm{~cm}$ from the CRT so that three character spaces subtended a visual angle of $1^{\circ}$. This position was maintained by using a bite plate mounted in a stationary position in front of the CRT. The testing room was dark except for an indirect light source that allowed the experimenter to adjust the eyetracking system as necessary. 
Materials and design. Forty sentence frames were constructed to include a category name and an exemplar name, as shown in Sentence 1:

The salesman said that the cloth was actually cotton which had been dyed.

The information contained in the sentence frame was intended to be neutral with regard to the category and its exemplars. The exemplar always followed the category name, and a prepositional phrase or a relative clause followed the exemplar so that the target word would not be the final word in the sentence. This was done to separate end-of-sentence slowdown effects (Just \& Carpenter, 1980) from processing time on the target word.

Each sentence frame and eight versions, produced by orthogonal combinations of exemplar typicality, prime type, and priming interval. An example of a sentence frame in each of its eight forms can be seen in Table 1. Exemplar typicality was manipulated by using a high-typicality exemplar (e.g., cotton) in half of the sentences and a low-typicality exemplar (e.g., canvas) in the other half. Prime type was either a category name that corresponded to the exemplars (e.g., cloth) or a neutral word, such as thing, stuff, man, guy, or fellow. The relative distance between the prime and the exemplar (priming interval) was also manipulated by inserting a relative clause or a phrase between the two critical words for half of the sentences. This additional material was written to be linguistically appropriate but neutral with respect to the category and its exemplars. Appendix A contains a complete list of the stimulus sentences used in Experiment 1.

Categories and exemplars. Typicality ratings were obtained for exemplars from 50 of the Battig and Montague (1969) categories. Using instance dominance (i.e., likelihood of producing an instance given a category name), exemplars were selected from the norms to create two distinct groups, one of very high instance dominance and one of moderately low instance dominance. To avoid idiosyncratic associations, items having extremely low instance dominance

Table 1

An Example Sentence from Experiment 1

$$
\text { Short Priming Interval }
$$

Primed

High Typicality

Low Typicality

Unprimed

High Typicality

Low Typicality

The salesman said that the cloth was actually cotton which had been dyed. The salesman said that the cloth was actually canvas which had been dyed

The salesman said the stuff was actually cotton which had been dyed.

The salesman said that the stuff was actually canvas which had been dyed.

Long Priming Interval

Primed

High Typicality

Low Typicality

Unprimed

High Typicality

Low Typicality
The salesman said that the cloth which they thought was so pretty was actually cotton which had been dyed.

The salesman said that the cloth which they thought was so pretty was actually canvas which had been dyed.

The salesman said that the stuff which they thought was so pretty was actually cotton which had been dyed.

The salesman said that the stuff which they thought was so pretty was actually canvas which had been dyed. were not selected. The number of exemplars selected from each category was not constant, but the average number was 16 . Twentytwo judges rated the category exemplars on a 7-point scale using Rosch's (1975) instructions.

Two exemplars from each category were chosen using the following criteria: (1) One item was selected from the three or four words having the highest typicality ratings for that category. (2) A second word was selected from the medium- or low-typicality words. To avoid words that might be considered nonmembers, no word with an average rating of less than 6 (with 7 as the lower extreme) was used. (3) The two exemplars in a pair had the same number of letters and were matched for frequency using the Kucera and Francis (1967) norms. The high-typicality items had a mean typicality rating of $1.54(1=$ highest rating $)$ and a mean word frequency of 30.58. The low-typicality items had a mean typicality rating of 4.28 and a mean word frequency of 28.0 .

Stimulus sets. Each subject read 40 experimental sentences and 20 filler sentences that were randomly ordered to make a stimulus set. Each stimulus set contained 5 sentences in each experimental condition, and only one condition was presented from each sentence frame. Across subjects, all eight conditions were presented an equal number of times for each sentence frame.

The sentences were presented one at a time to the subject. Each sentence occupied two to four lines on the screen, with a limit of 42 characters per line. The exemplar was never the first or last word on a line.

Procedure. When a subject arrived, a bite plate was made using a fast-hardening dental plastic. The bite plate was then mounted in a standard position in front of the CRT. The subject's chair was adjusted for comfort. During this initial period, the subject's eyes adapted to the darkened room.

The experimenter calibrated the eyetracker by adjusting the position of the subject's head to maximize reflection of light from the eye. Accurate tracking was tested to the horizontal and vertical limits of the tracking system. When tracking was achieved, a cross extending $.5^{\circ}$ in the vertical and horizontal directions around the center of fixation was projected on the CRT. This cross followed the eye as it moved across the screen. Prior to presentation of each sentence during the experiment, this cross appeared and was used to check the continuing accuracy of the calibration. The overlap of this cross with a fixation cross at the left side of the screen signaled that the subject was ready and that the experimenter could initiate a reading trial.

Subjects were given a brief explanation of the eyetracker. The purpose of the experiment was described in general terms as a study of what the eyes do when people read. Participants were told to read normally and for comprehension, as closely as they would read a textbook when they were studying. Memorization was explicitly discouraged. Instead, they were asked to read so that they could reproduce a close paraphrase of the sentence if asked to do so. Rereading was permitted, but subjects were told that a single pass through the sentence would usually be sufficient for comprehension.

\section{Results and Discussion}

Approximately $10 \%$ of the trials were eliminated because of track losses due to blinks and return sweeps. Another $6 \%$ of the cases were eliminated because the critical region, the area around the target exemplar, was not fixated.

The mean priming interval was calculated from the beginning of the first fixation on the category name to the beginning of the first fixation on the exemplar. This measure is analogous to the stimulus onset asynchrony (SOA) between prime and target words in studies in which timing is under the experimenter's control. The mean prim- 
ing interval was $488 \mathrm{msec}$ for all sentences in the short delay condition and 1,247 msec for sentences in the long delay condition.

Table 2 shows the mean processing times in milliseconds separated by levels of priming, exemplar typicality, and priming interval. These values and marginal means are from the subjects analysis. Two analyses of variance were performed, one treating subjects as a random factor and one treating sentences as a random factor. Exemplars following a category prime were processed faster $(235 \mathrm{msec})$ than those following a neutral prime $(264 \mathrm{msec})$. This effect of prime type was significant in the subject analysis $[F(1,15)=5.782, p<.05$, SED $=$ $23.5 \mathrm{msec}]$ and in the sentence analysis $[F(1,39)=6.842$, $p<.025, \mathrm{SED}=20.8 \mathrm{msec}]$. The only difference between the sentence contexts for the critical items at the point of measurement was the prime. Use of the category name earlier in the sentence significantly facilitates processing of this target item. This finding alone sufficiently demonstrates that semantic context can influence word processing time as measured by fixation duration. All other findings will serve to clarify the meaning of this context effect.

High-typicality exemplars were processed faster (239 msec) than low-typicality exemplars $(260 \mathrm{msec})$. This effect was significant in the subject analysis $[F(1,15)$ $=11.702, p<.01, \mathrm{SED}=12.6 \mathrm{msec}]$ and in the sentence analysis $[F(1,39)=4.129, p<.05$, SED $=$ $19.4 \mathrm{msec}$ ] and is consistent with the prediction of the spreading activation model. However, if the typicality effect was due to different levels of activation of category exemplars produced by the category prime, then there should have been little or no typicality effect in the unprimed condition. This was not the case. Prime type and exemplar typicality did not interact $(F<1.0)$, and, in fact, the typicality effect was slightly greater in the unprimed condition (mean difference $=24 \mathrm{msec}$ ) than in the primed condition (mean difference $=18 \mathrm{msec}$ ).

It is interesting to note that Neely (1977) also found faster processing for high-category-dominance exemplars than for low-dominance items in an unprimed condition. He suggested that word frequency differences might account for the finding, a possibility that has been reduced by frequency controls in the present experiment. In several

Table 2

Mean Fixation Durations (in Milliseconds) on Target Exemplars in Experiment 1

\begin{tabular}{ccc}
\hline & \multicolumn{2}{c}{ Exemplar Typicality } \\
\cline { 2 - 3 } & High & Low \\
\hline & Primed & \\
Short & 224 & 246 \\
Long & 228 & 244 \\
Mean & 226 & 245 \\
& Unprimed & \\
Short & 265 & 276 \\
Long & 238 & 276 \\
Mean & 252 & 276 \\
\hline
\end{tabular}

experiments using a categorization task, Rosch (1975) reported strong main effects of typicality and category priming, but, under most conditions, no interaction of the two factors. Rosch argues that the underlying categories contained in semantic memory have a category structure and that accessing this structure will lead to typicality effects. Along these lines, we could argue that sentence comprehension demands the retrieval of this category information, even in the case that the category must be inferred from context or derived from the exemplar name.

The processing time for targets in the short prime interval $(253 \mathrm{msec})$ did not differ significantly from the processing time for targets in the long prime interval (247 msec) $(F<1.0, \mathrm{SED}=14.2 \mathrm{msec}$ for the subjects analysis and SED $=18.4 \mathrm{msec}$ for the sentence analysis). Priming interval did not interact with either of the other two factors (both $F \mathrm{~s}<1.0$ ). Other studies using isolated word contexts have reported different patterns of results due to changes in priming interval. However, in a sentence context, priming interval had no effect. This result is consistent with those found using a phoneme monitoring task (Foss, 1982), in which facilitation persisted at different sentence lengths provided that the topic of the sentence remained unchanged.

There are two reasonable interpretations of these results. One is that the facilitation effects reflect word encoding processes that are consistent with the spreading activation model. The priming results are predicted by this model, but the typicality results are not. The typicality effect may have been due to differences between the words that were selected as high- and low-typicality exemplars. The low-typicality words may have been harder to process than the high-typicality words, despite the selection procedures that equated them on length and frequency. One way to control for this problem is to change the context and to use the same critical item in all conditions. This precaution is used in Experiment 2.

The second explanation is that the typicality effect reflects time to integrate the words into the sentence, rather than search time through the semantic network to access the word. High-typicality words may have been more easily integrated with the sentence frame than lowtypicality words. If we wish to maintain the spreading activation account of the priming effect, then two different processes must be influencing fixation time on the critical items: facilitation of word encoding processes, reflected in the priming effect, and differential levels of difficulty in integrating words into the sentence context, reflected in the typicality effect.

In Experiment 2, we investigated whether or not the priming effect might also be due to integration of the word into the sentence, rather than to a spreading activation search in lexical access. If both kinds of facilitation effects found in Experiment 1 were due to processes that integrate the word with the sentence context, then the facilitation should be dependent on the cognitive processes used to relate words to one another during sentence comprehension. In Experiment 2, we select one aspect of a 
sentence comprehension model and examine its relationship to facilitation effects due to priming. If the priming effect is constrained by the sentence comprehension mechanism, then it cannot be adequately explained by the automatic activation of the semantic network.

The differences in processing time between primed and unprimed conditions in Experiment 1 have heretofore been interpreted as facilitation effects. It is possible that the differences were actually due to processing difficulties created by sentences in the unprimed condition containing vague words, such as stuff and guy. Such effects would more appropriately be interpreted as inhibitory or slowdown effects. This problem is addressed in Experiment 2 .

\section{EXPERIMENT 2}

Experiment 2 investigated how the structure of the sentence affected lexical processing. Recent research in psycholinguistics has shown that sentences are structured according to syntactic units prior to full semantic interpretation (Frazier et al., 1983; Rayner, Carlson, \& Frazier, 1983). Some models suggest that sentence comprehension and integration of concepts are completed in stages governed by the clausal units of the input sentence (J. A. Fodor, Bever, \& Garrett, 1974; Frazier \& J. D. Fodor, 1978). Words are integrated with other words in the same clausal constituent before any higher level discourse integration takes place. If clausal constituents function as the domain for integration of individual lexical items, we would expect that lexical integration would only be facilitated by word associates within the same clause.

In contrast, if priming is due to activation of a concept in semantic memory, it should only be sensitive to factors that influence the rate of decay of activation, but clause boundaries should have no effect. Neely (1977) has suggested that semantic priming beyond the initial automatic phase (lasting less than $700 \mathrm{msec}$ ) requires active maintenance. Foss (1982) proposed that sentence comprehension processes maintain activation of important text elements beyond the time that residual activation would persist from the same concepts in a list structure. Although Foss argues that activation continues as long as the topic of the text is unchanged, we suggest that the first phase of semantic integration is clausally bounded and that activation dependent on the initial representation of a lexical item should not be maintained across clause boundaries. The sentences in Experiment 2 were constructed so that the prime word and the target word either occurred within the same clause or in separate clauses. If semantic priming is due to integration of concepts within clausal processing units, priming should occur within a clause but not between clauses. If priming effects are due to facilitation of lexical lookup or if they arise from discourse-level information, we expect priming to occur in both the same clause and between clause conditions.

\section{Method}

Subjects. Twenty-eight members of the University of Massachusetts community were paid to participate in the experiment. All subjects had normal uncorrected vision. None of them had ever been in an eye-movement experiment before.

Apparatus and procedure. The apparatus and procedure were the same as in Experiment 1.

Materials and design. Forty-two sentence frames were written to include a prime and target word. Three prime conditions were used: associative, nonassociative, and neutral. Sentence 2 shows the associative prime condition, in which the prime word is king and the target word is queen:

\section{The guard saluted the king and the queen in the carriage, but they didn't notice.}

The associative primes were selected from 42 pairs of primary associates from the Shapiro and Palermo norms (1969). The nonassociative prime and neutral prime were both control conditions. In the nonassociative condition, the prime word was selected to be as appropriate in the sentence frame and as concrete as the associative primes, but without the direct relationship to the target word (e.g., ambassador substituted for king). In the neutral prime condition, as in Experiment 1, the prime words were general class terms that carried little specific semantic information (e.g., man or thing).

There were two syntactic boundary conditions: same clause and different clause. In the same-clause conditions, the word associates both occurred in the first clause of the sentence. In the differentclause conditions, a clause boundary, explicitly marked by a comma, intervened between the first and second words in the associative pair. The words that intervened between the associates (as well as all of the preceding sentence) were identical for both sentence types. Since parafovial information can potentially affect processing time, the words immediately following the target associate were also identical for all conditions.

A neutral control sentence was used to estimate the basic processing time for the target word in each frame, independent of prior processing load. This sentence contained the target in the second clause and was similar to the experimental sentences, but the initial constituent was a separate sentence that did not contain the prime. The seven versions of the example sentence are presented in Table 3.

Each subject read 42 sentences with 6 sentences in each of the seven experimental conditions. Each sentence frame appeared only once for a given subject, and across subjects all sentences were presented an equal number of times in each experimental condition. A complete list of sentences can be found in Appendix B.

Table 3

An Example Sentence from Experiment 2 Same Clause

Associative

Prime

Nonassociative

Prime

Neutral Prime

Associative

Prime

Nonassociative

Prime

Neutral Prime

Control
The guard saluted the king and the queen in the carriage, but they didn't notice.

The guard saluted the ambassador and the queen in the carriage, but they didn't notice. The guard saluted the man and the queen in the carriage, but they didn't notice.

\section{Different Clause}

The guard saluted the king, and the queen in the carriage looked annoyed.

The guard saluted the ambassador, and the queen in the carriage looked annoyed.

The guard saluted the man, and the queen in the carriage looked annoyed.

The crowd jeered loudly. The queen in the carriage looked annoyed. 


\section{Results and Discussion}

Approximately $6 \%$ of the cases were eliminated due to track losses and blinks. Another $2 \%$ of the cases were not included because the subject did not fixate within the critical region.

Table 4 shows the mean processing times on target nouns for each of the six experimental conditions and for the neutral control. Two analyses of variance of boundary condition $\times$ prime type were performed, one treating subjects as a random factor and one treating items as a random factor. The neutral control was not included in these analyses.

The targets preceded by the associative prime were processed faster $(228 \mathrm{msec})$ than the same targets preceded by the nonassociative prime $(251 \mathrm{msec})$ or the neutral prime $(256 \mathrm{msec})$. This priming effect was significant in the subjects analysis $[F(2,54)=5.676$, $p<.01, \mathrm{SED}=12.6 \mathrm{msec}]$ and in the sentence analysis $[F(2,78)=6.809, p<.01, \mathrm{SED}=11.5 \mathrm{msec}]$. This result generalizes the associative priming effect found for class membership in Experiment 1 to association determined by co-occurrence frequency. Furthermore, because the same word served as the target item in all conditions, any explanations of the priming effect based on word familiarity factors may be discounted.

The critical prediction of the clausal hypothesis was that priming effects should be more apparent when both the prime and the associated target item were in the same clause. The alternative prediction, based on the spreading activation view outlined in Experiment 1, predicted that priming is independent of structural processes and is confined to the processing of lexical relations.

The prediction of the clausal hypothesis was confirmed by the significant interaction of the boundary condition with the type of prime in the subject analysis $[F(2,54)=$ $3.971, p<.025, \mathrm{SED}=10.5 \mathrm{msec}]$ and in the sentence analysis $[F(2,78)=3.26, p<.05$, SED $=15.8 \mathrm{msec}]$. This interaction indicates that the priming effect was greater when the associates were in the same clause than when they were separated by a clause boundary. Overall, processing time for the different-clause condition ( $243 \mathrm{msec}$ ) did not differ from the same-clause condition (244 msec) $[F<1.0$, SED $=10.3 \mathrm{msec}$ for the subject analysis and SED $=11.7 \mathrm{msec}$ for the sentence analysis]. This finding suggests that there is no basic difference in difficulty for the sentences in the two conditions.

Table 4

Mean Gaze Durations (in Milliseconds) on

Target Exemplars in Experiment 2

\begin{tabular}{lcccc}
\hline & & \multicolumn{2}{c}{ Type of Prime } & \\
\cline { 2 - 3 } & Associative & Nonassociative & Neutral \\
\cline { 2 - 3 } Same Clause & 219 & 246 & man-queen \\
Different Clause & 237 & 255 & 267 \\
& & Control & \\
\hline
\end{tabular}

In order to evaluate these results more closely, planned comparisons among individual means were conducted using multiple $t$ ratios using the data and the mean standard error term from the subject analysis (Kirk, 1968). In the same-clause condition, targets in the associative prime condition were processed significantly faster than in either the nonassociative prime condition $(t=2.38, p<.02)$ or the neutral prime condition $(t=4.231, p<.001)$. The difference between the nonassociative and neutral primes was not significant $(t=1.851, p<.10)$; however, the effect was marginal. The neutral prime is the same as the unprimed condition in Experiment 1. The marginal difference between the nonassociative and neutral primes suggests that the priming effect in Experiment 1 may be partially due to a slowdown in processing in the unprimed condition. As Jonides and Mack (1984) have suggested, some control conditions may introduce additional processing due to the nature of the control. In the present experiment, the neutral prime condition is unusually abstract given the sentence frame. This might produce a more difficult context into which the target word may fit, which would appear as an inhibitory effect on processing time on the target item. Consequently, the claim that the priming effect in Experiment 1 is partially due to a slowdown in processing in the unprimed condition cannot be entirely ruled out.

The three prime types in the different-clause condition did not significantly differ from each other. When the prime and the target occurred in separate clauses, there was no effect of the prime type on the processing time for the target. This result supports the clausal hypothesis and suggests that processing time on words within a sentence context is controlled by structural factors, even where intralexical word associations may be capable of influencing processing.

The control sentence condition provided an additional way to evaluate whether the priming effect was facilitation or inhibition. This control produced a mean processing time of $242 \mathrm{msec}$. For the same-clause sentences, this mean was significantly slower than for sentences in the associative prime condition $(t=2.027, p<.05)$ and faster than for those in the neutral prime condition $(t=$ 2.203, $p<.05$ ). None of the processing times for the different prime types in the different-clause conditions differed significantly from processing times for the control condition. This result is consistent with the other control conditions. Although it is difficult to establish an unequivocal baseline, the use of multiple controls (Jonides \& Mack, 1984) provides some evidence for whether these effects are facilitative or inhibitory. The pattern of results shows that the associative priming effect is clearly facilitative. This experiment used three different comparison conditions: the nonassociative prime, the neutral prime, and the control-sentence condition. In all three conditions, the associative prime condition for the same-clause case was significantly faster than the comparison condition. Regardless of which baseline is best, processing is facilitated by the prior occurrence of an associate in the same clause. 


\section{GENERAL DISCUSSION}

These two experiments showed that semantic priming effects occur during normal reading in response to specific lexical information in the current sentence. In Experiment 1 , processing of a category exemplar was facilitated by the prior occurrence of a category name in the sentence. In addition, typical exemplars were processed more quickly than atypical exemplars in both the primed and unprimed conditions. In Experiment 2, processing time for a target item was facilitated by the prior occurrence of a primary associate. By using eye-movement monitoring, these effects were detected on-line during normal reading. Consequently, they reflect a change in the difficulty of understanding the sentence, rather than a secondary response to the experimental task.

Theoretical accounts often attribute priming effects to facilitation of lexical access (e.g. , Becker, 1980; Forster, 1978). Although models vary, we have characterized this facilitation as activation of the prime word spreading in the semantic network to the target word, decreasing the search time or recognition threshold of the target word. However, several results in our experiments argue that differences in word processing time cannot be attributed entirely to lexical access. In Experiment 1, the typicality effect occurred in both the primed and unprimed conditions, apparently due to the difficulty of integrating lowtypicality exemplars into the sentence frames. This interpretation is reinforced by the priming effects found in Experiment 2, in which the timing of processes involved in syntactic structuring and semantic interpretation of sentences was not independent of the facilitation effect due to priming.

Foss (1982), using results from experiments with spoken sentences, has argued that active maintenance of the prime word is necessary for a facilitation effect to occur and that this maintenance takes place in sentence processing at the level of propositions critical to discourse level integration. In Experiment 2, priming occurred when two associates were in the same clause, but not when they were separated by a clause boundary. Thus, our results concur with his prediction that activation does not dissipate immediately when words are processed in a sentence context, but, in contrast with Foss's findings, the immediate syntactic constituent appears to be the critical region for such facilitation. There are undoubtedly many discourse integration effects and overall sentence comprehension effects that can be detected during reading, but the fixation duration measure appears particularly sensitive to structurally bound phenomena (cf. Rayner et al., 1983).

If priming effects are constrained by sentence structure, they are more likely to result from a process such as postaccess integration, which uses relational information in the sentence, than from a process such as the automatic spread of activation that is insensitive to sentence structure (see Cairns, Cowart, \& Jablon, 1981, for a similar suggestion). Chumbley and Balota (1984) have recently reported evidence from experiments using the lexical decision task that is compatible with the postaccess claim. They found that the lexical decision task, which has been the most important procedure for studying context priming, is primarily influenced by postaccess processes related to the meaning of the primed item.

The effect of the syntactic boundary on priming has important implications for sentence processing models. Modular processing models argue that lexical, syntactic, and semantic processing is done in separate subsystems, as information completed in one module is passed on to the next. Some of these models hold that the syntactic module organizes the words into clauses that are the units of processing for semantic analysis. By contrast, interactive processing models argue that all types of information are available immediately to affect processing at any level. These models assume that syntax is a type of information that can affect the difficulty of understanding a sentence, but it should not constrain when other information can be used in the processing system. The structural constraint found in Experiment 2 provides support for a modular model of sentence comprehension.

Finally, the results of these experiments add to the growing body of evidence that fixation duration can be used to detect differences in difficulty of language comprehension processes at specific locations. Fixation times on the target word were affected by aspects of the meaning and structure of the current sentence context. The immediate appearance of such effects while the reader was fixating the critical word is compatible with direct control models of eye movements (Rayner \& Pollatsek, 1981; also the eye-mind assumption of Just \& Carpenter, 1980), which claim that there is no buffer-mediated delay between input of visual information and processes that lead to higher levels of sentence comprehension. Readers are executing some processes of lexical access and sentence integration as rapidly as the words can be fixated and perceived. The goal of future research is to specify the full range of processes that are completed immediately and to discover the structural constraints that delay or inhibit others.

\section{REFERENCES}

Antos, S. J. (1979). Processing facilitation in a lexical decision task. Journal of Experimental Psychology: Human Perception \& Performance, 5, 527-545.

Balota, D. A., Pollatsek, A., \& Rayner, K. (1985). The interaction of contextual constraints and parafoveal visual information in reading. Cognitive Psychology, 17, 364-390.

Battig, W. R., \& Montague, W. E. (1969). Category norms for verbal items in 56 categories: A replication and extension of the Connecticut category norms. Journal of Experimental Psychology Monograph, 80(3, Pt. 2).

BECKER, C. A. (1979). Semantic context and word frequency effects in visual word recognition. Journal of Experimental Psychology: Human Perception \& Performance, 5, 252-259.

BECKER, C. A. (1980). Semantic context effects in visual word recognition: An analysis of semantic strategies. Memory \& Cognition, 8 , 493-512.

Bever, T. G., \& HURTIG, R. R. (1975). Detection of a nonlinguistic 
stimulus is poorest at the end of a clause. Journal of Psycholinguistic Research, 4, 1-7.

CAIRnS, H. S., CowarT, W., \& JABLON, A. D. (1981). Effects of prior context upon the integration of lexical information during sentence processing. Journal of Verbal Learning \& Verbal Behavior, 20 , 445-453.

Carpenter, P. A., Daneman, M. (1981). Lexical retrieval and error recovery in reading: A model based on eye fixations. Journal of Verbal Learning \& Verbal Behavior, 20, 137-160

Carpenter, P. A., \& Just, M. A. (1981). Cognitive processes in reading: Models based on readers' eye fixations. In A. M. Lesgold \& C. A. Perfetti (Eds.), Interactive processes in reading (pp. 177-213). Hillsdale, NJ: Erlbaum.

Chumbley, J. I., \& Balota, D. A. (1984). A word's meaning affects the decision in lexical decision. Memory \& Cognition, 12, 590-606.

Collins, A. M., \& LofTus, E. F. (1975). A spreading-activation theory of semantic processing. Psychological Review, 82, 407-428.

Cornsweet, T. N., \& Crane, H. D. (1973). Accurate two-dimensional eye tracker using first and fourth Purkinje images. Joumal of the Op tical Society of America, 63, 921-928.

DE GRoot, A. M. B. (1983). The range of automatic spreading activation in word priming. Joumal of Verbal Learning \& Verbal Behavior, 22, 417-436.

DE Groot, A. M. B., Thomassen, A. J. W. M., \& Hudson, P. T. W. (1982). Associative facilitation of word recognition as measured from a neutral prime. Memory \& Cognition, 10, 358-370.

den Heyer, K., Briand, K., \& Dannenbring, G. L. (1983). Strategic factors in a lexical-decision task: Evidence for automatic and attention-driven processes. Memory \& Cognition, 11, 374-381.

DEN HeYer, K., Briand, K., \& SMITh, L. (1985). Automatic and strategic effects in semantic priming: An examination of Becker's verification model. Memory \& Cognition, 13, 228-232.

Ehrlich, K., \& Rayner, K. (1983). Pronoun assignment and semantic integration during reading: Eye movements and immediacy of processing. Joumal of Verbal Leaming \& Verbal Behavior, 22, 75-87.

EHRLICH, S. F., \& RAYNER, K. (1981). Contextual effects on word perception and eye movements during reading. Journal of Verbal Leaming \& Verbal Behavior, 20, 641-655.

Fischler, I. (1977a). Associative facilitation without expectancy in a lexical decision task. Joumal of Experimental Psychology: Human Perception \& Performance, 3, 18-26.

FisCHLER, I. (1977b). Semantic facilitation without association in a lexical decision task. Memory \& Cognition, 5, 335-339.

Fischler, I., \& Bloom, P. A. (1979). Automatic and attentional processes in the effects of sentence contexts on word recognition. Journal of Verbal Learning \& Verbal Behavior, 18, 1-20.

FisCHLER, I., \& BLOOM, P. A. (1980). Rapid processing of the meaning of sentences. Memory \& Cognition, 8, 216-225.

Fischler, I. S., \& BLOOM, P. A. (1985). Effects of constraint and validity of sentence contexts on lexical decisions. Memory \& Cognition, 13, 128-139.

Fodor, J. A., Bever, T. G., \& Garrett, M. F. (1974). The psychology of language. New York: McGraw-Hill.

Forster, K. I. (1978). Accessing the mental lexicon. In E. Walker (Ed.), Explorations in the biology of language (pp. 139-174). Montgomery, VT: Bradford

FoRSTER, K. I. (1979). Levels of processing and the structure of the language processor. In W. E. Cooper \& E. C. T. Walker (Eds.), Sentence processing (pp. 27-85). Hillsdale, $\mathrm{NJ}$ : Erlbaum.

Foss, D. J. (1982). A discourse on semantic priming. Cognitive Psychology, 14, 590-607.

Frazier, L., Clifton, C., \& Randall, J. (1983). Filling gaps: Decision principles and structure in sentence comprehension. Cognition, 13, 187-222.

Frazier, L., Fodor, J. D. (1980). The sausage machine: A two stage parsing model. Cognition, 6, 291-325.

FRAZIER, L., \& RAYNER, K. (1982). Making and correcting errors during sentence comprehension: Eye movements in the analysis of structurally ambiguous sentences. Cognitive Psychology. 14. 178-210.

Freeman, S. E. \& Forster, K. I. (1985). The psychological status of overgenerated sentences. Cognition, 19, 101-131.
GARNHAM, A. (1981). Anaphoric reference to instances, instantiated and non-instantiated categories: A reading time study. British Journal of Psychology, 72, 377-384.

GARROD, S., \& SANFORD, A. (1977). Interpreting anaphoric relations: The integration of semantic information while reading. Journal of Verbal Learning \& Verbal Behavior, 16, 77-90.

Gough, P. B., Alford, J. A., \& Holley-Wilcox, P. (1981). Words and context. In O. J. L. Tzeng \& H. Singer (Eds.), Perception of print: Reading research in experimental psychology (pp. 85-102). Hillsdale, NJ: Erlbaum.

INHOFF, A. W. (1984). Two stages of word processing during eye fixations in the reading of prose. Journal of Verbal Learning \& Verbal Behavior, 23, 612-624.

Inhoff, A. W., Lima, S. D., \& Carroll, P. J. (1984). Contextual effects on metaphor comprehension in reading. Memory \& Cognition, 12 , 558-567.

JONIDES, J., \& MACK, R. (1984). On the cost and benefit of cost and benefit. Psychological Bulletin, 96, 29-44.

JUST, M. A., \& CARPENTER, P. A. (1978). Inference processes during reading: Reflections for eye fixations. In J. W. Senders, D. F. Fisher, $\&$ R. A. Monty (Eds.), Eye movements and the higher psychological functions (pp. 157-174). Hillsdale, NJ: Erlbaum.

Just, M. A., Carpenter, P. A. (1980). A theory of reading: From eye fixations to comprehension. Psychological Review, 87, 329-354.

KıRK, R. E. (1968). Experimental design: Procedures for the behavioral sciences. Belmont, CA: Brooks/Cole.

KLEIMAN, G. M. (1980). Sentence frame contexts and lexical decisions: Sentence-acceptability and word-relatedness effects. Memory \& Cognition, 8, 336-344.

KuČera, H., \& Francis, W. N. (1967). Computational analysis of present-day American English. Providence, RI: Brown University Press.

LoFTUs, E. F. (1975). Spreading activation within semantic categories: Comments on Rosch's "Cognitive representations of semantic categories." Journal of Experimental Psychology: General, 104, 234-240.

LORCH, R. F. (1982). Priming and search processes in semantic memory: A test of three models of spreading activation. Journal of Verbal Learning \& Verbal Behavior, 21, 468-492.

Marslen-Wilson, W. D., \& Welsh, A. (1978). Processing interactions and lexical access during word recognition in continuous speech. Cognitive Psychology, 10, 29-63.

Matin, E. (1974). Saccadic suppression: A review and an analysis. Psychological Bulletin, 81, 899-917.

McConkIE, G. W., \& Rayner, K. (1975). The span of the effective stimulus during a fixation in reading. Perception \& Psychophysics, 17, 578-586.

McConkie, G. W., Zola, D., Blanchard, H. E., \& Wolverton, G. S. (1982). Perceiving words during reading: Lack of facilitation from prior peripheral exposure. Perception \& Psychophysics, 32, 271-281.

Meyer, D. E., \& Schvaneveldt, R. W. (1971). Facilitation in recognizing pairs of words: Evidence of a dependence between retrieval operations. Joumal of Experimental Psychology, 90, 227-234.

Morton, J. (1964). The effects of context on the visual duration thresholds for words. British Journal of Psychology, 55, 165-180.

NeELy, J. H. (1976). Semantic priming and retrieval from lexical memory: Evidence for facilitatory and inhibitory processes. Memory \& Cognition, 4, 648-654.

NeELY, J. H. (1977). Semantic priming and retrieval from lexical memory: Roles of inhibitionless spreading activation and limited capacity attention. Journal of Experimental Psychology: General, 106, 226-254

RAYNER, K. (1977). Visual attention in reading: Eye movements reflect cognitive processes. Memony \& Cognition, 5, 443-448.

RaYNer, K. CARLSON, M., \& Frazier, L. (1983). The interaction of syntax and semantics during sentence processing: Eye movements in the analysis of semantically biased sentences. Joumal of Verbal Learning \& Verbal Behavior, 22, 358-374.

Rayner, K., INhoff, A. W., Morrison, R. E., Slowiaczek, M. L., \& Bertera, J. H. (1981). Masking of foveal and parafoveal vision 
during eye fixations in reading. Journal of Experimental Psychology: Human Perception \& Performance, 7, 167-179.

Rayner, K., \& Pollatsek, A. (1981). Eye movement control during reading: Evidence for direct control. Quarterly Joumal of Experimental Psychology, 33A, 351-373.

Rayner, K., Well, A. D., Pollatsek, A., \& Bertera, J. H. (1982). The availability of useful information to the right of fixation in reading. Perception \& Psychophysics, 31, 537-550.

Rosch, E. H. (1973). On the internal structure of perceptual and semantic categories. In T. E. Moore (Ed.), Cognitive development and the acquisition of language (pp. 111-144). New York: Academic Press.

Rosch, E. (1975). Cognitive representations of semantic categories. Journal of Experimental Psychology: General, 104, 192-233.

Rumelhart, D. E., \& MCClelland, J. L. (1982). An interactive activation model of context effects in letter perception: Part 2. Psychological Review, 89, 60-94.

Sanocki, T., Goldman, K., Waltz, J., Cook, C., Epstein, W., \& ODEN, G. C. (1985). Interaction of stimulus and contextual information during reading: Identifying words within sentences. Memory \& Cognition, 13, 145-157.

Schuberth, R. E., \& Eimas, P. D. (1977). Effects of context on the classification of words and nonwords. Journal of Experimental Psychology: Human Perception \& Performance, 3, 27-36.

Schvaneveldt, R. W., \& MeYer, D. E. (1973). Retrieval and comparison processes in semantic memory. In S. Kornblum (Ed.), Attention and performance IV (pp. 393-409). New York: Academic Press.

Schwanenflugel, P. J., \& Shoben, E. J. (1985). The influence of sentence constraint on the scope of facilitation for upcoming words. Journal of Memory \& Language, 24, 232-252.

Shapiro, S. I., \& Palermo, D. S. (1969). An atlas of normative free association data. Psychonomic Monograph Supplement, 2, 219-250.

Stanovich, K. E., \& West, R. F. (1979). Mechanisms of sentence context effects in reading: Automatic activation and conscious attention. Memory \& Cognition, 7, 77-85.

Tulving, E., \& Gold, C. (1963). Stimulus information and contex tual information as determinants of tachistoscopic recognition of words. Journal of Experimental Psychology, 66, 319-327.

Tulving, E., Mandler, G., \& Baumal, R. (1964). Interaction of two sources of information in word recognition. Canadian Journal of $P_{s y-}$ chology, 18, 62-71.

VolKMANN, F. C. (1962). Vision during voluntary saccadic eye movements. Journal of the Optical Society of America, 52, 571-578.

VoNK, W. (1984). Eye movements during comprehension of pronouns. In A. G. Gale \& F. Johnson (Eds.), Theoretical and applied aspects of eye movement research (pp. 203-212). Amsterdam: North-Holland.

ZolA, D. (1984). Redundancy and word perception during reading. Perception \& Psychophysics, 36, 277-284.

\section{APPENDIX A}

\section{Stimulus Sentences from Experiment 1}

1. He swore that he did not use <ALCOHOLIC BEVERAGES, THAT STUFF $>$, but [the detectives saw that] the $<$ RUM, RYE $>$ in the bottle was almost gone.

2. They could not see the <ANIMAL, THING $>$ [anywhere in the distance], but the <LION, BULL > roared loudly enough to scare them away.

3. James was so tired, he did not realize the <BEVERAGE, THING $>$ [he had bought] was a $<$ SODA, MALT $>$ until he drank it.

4. The housekeeper remarked that the <BIRD, THING > [which passed by the window] was a $<$ SPARROW, VULTURE $>$ which was building a nest.

5. The stupid nurse looked at each <PART OF HIS BODY, AND EVERY THING $>$ [with a very serious expression] except for his <LEGS, SKIN>, which were (was) the reason he had come to the clinic.

6. Because of the inspector's training, the first <PART OF A BUILDING, THING ON HIS LIST $>$ he checked [upon his arrival] was the <CEILING, CORNERS $>$ in several rooms to see if the work was done well.

7. John did not know that they were constructing < A RELIGIOUS BUILDING, SOME THING $>$ [at the end of the street] until the <CHAPEL, MOSQUE > was nearly completed.

8. The professor was amused that the strange $<$ CHEMICAL ELEMENT, NEW STUFF $>$ [which was confusing everyone] was just $<$ CARBON, SILVER $>$ from a test tube they had forgotten to clean.

9. He noted with some embarrassment that the approaching $<$ CLERGYMAN, PERSON $>$ [in the heavy overcoat] was the <PRIEST, RECTOR > whose car he had hit the day before.

10. The salesman said that the $<$ CLOTH, STUFF $>$ [which they thought was so pretty] was actually $<$ COTTON, CANVAS $>$ which had been dyed.

11. When he returned home, he discovered that all of his $<$ CLOTHING, THINGS > [that had been in the closet], even his <PANTS, SCARF>, had been stolen.

12. Although he stated that he was not aware of the <CRIME, EVENT $>$, [he was not surprised when] they said $<$ ROBBERY, TREASON $>$ was the charge they would level against him.

13. Just when the officials believed they had controlled the $<$ DISEASE, CONDITION > [and were about to leave], more <MALARIA, MEASLES > was (were) reported in the area.

14. In the early days, the unit which farmers used to measure $<$ DISTANCE, THINGS > was [believed by historians to be] <YARDS, STEPS > when plots of land were being divided.

15. The surprised people found that the <DWELLING, THING $>$ [they could see in the distance] was a $<$ CABIN, MOTEL $>$ near the shore.

16. Mr. Dalton was upset that he was not <ELECTED TO OFFICE, GIVEN HIS TURN > [in the local men's club] as <PRESIDENT, SECRETARY $>$, despite all his hard work.

17. He claimed that he loved this kind of <FISH, FOOD>, but [it was obvious to everyone that] he thought the $<$ HADDOCK, LOBSTER > tasted pretty bad.

18. She really appreciated the <FLOWERS, PRESENT > [when he gave them (it) to her] because the <DAISIES, ORCHIDS > meant that he cared about her feelings.

19. My date insisted that her portion had been ruined because the <FOOD SEASONING, ONLY THING $>$ [they had put] on it was <SALT, WINE > which had been added too liberally.

20. His sister searched through the box of <FOOTGEAR, THINGS > [in the basement] for the <BOOTS, PUMPS> she wore in messy weather.

21. The bowl was full of <FRUIT, THINGS $>$, [which had been beautifully arranged,] and some <APPLES, PRUNES > were on the bottom.

22. The fireman reported that the burning <FUEL, STUFF> [in the trash can in the garage] was <GASOLINE, CHARCOAL $>$ which was giving off toxic fumes.

23. The two women thought that the last of the <FURNITURE, THINGS $>$ [needing to be repaired] was the $<\mathrm{COUCH}$, CLOCK $>$ in the living room. 


\section{APPENDIX A (Continued)}

24. The old scientist said that the most interesting < GEOLOGICAL FORMATION, OF SUCH THINGS > [he could imagine studying] was a $<$ CANYON, HARBOR $>$, because it could take so many forms.

25. The boy liked to collect all kinds of < INSECTS, THINGS $>$ [that could be found in the woods] except $<$ WASPS, WORMS $>$, because they scared him.

26. The silly snob claimed that this <JEWEL, THING > [in the brown box] had to be a <DIAMOND, CRYSTAL> which had been poorly cut.

27. Although he was not an expert in working with this $<$ METAL, STUFF > , he found [to his relief] that the $<$ COPPER, COBALT $>$ could be manipulated when it was heated.

28. The store sold almost every type of <MUSIC, THING > [he could possibly imagine], including some $<$ CLASSICAL, SPIRITUAL > recordings which were very rare.

29. His father had decided on his <PROFESSION, FUTURE $>$, [without so much as a comment to him,] and a(n) < LAWYER, ARTIST > was what he was expected to become.

30. He looked on the shelf for < READING MATERIAL, SOME THING $>$ [to keep himself amused], but a $<$ NOVEL, BIBLE $>$ was all he found.

31. He told all his friends that he hated < SCIENCE, STUDYING > [because it required so much work], but his $<$ CHEMISTRY, NUTRITION $>$ class was worth the extra effort.

32. Looking through the telescope, my brother shouted that the <SHIP, SPOT > [we could just make out] was a $<$ DESTROYER, SUBMARINE $>$ going out to sea.

33. They first heard the sound of the $<$ SNAKE, THING $>$ [, though they had been very careful,] when the $<$ COBRA, ADDER $>$ attacked them.

34. The student admitted that he liked many <SPORTS, THINGS $>$ [which were a distraction from his work], and $<$ HOCKEY, HIKING > was by far his favorite activity.

35. I looked among the <CARPENTER'S TOOLS, ASSORTED THINGS $>$ [which were sitting in the hall] for a < HAMMER, CHISEL > to give my assistant.

36. She saw the missing <TOYS, THINGS > [behind the chair] with the <BALL, CLAY > which the children had forgotten to put away.

37. The retired gentleman wanted to remove the beautiful old $<$ TREE, THING > [and clear the area] to put a $<$ PINE, PALM $>$ in its place.

38. The woman liked experimenting with < VEGETABLES, THINGS $>$, so she [used her imagination and] put some $<$ CARROTS, PEANUTS $>$ in the fancy French soup.

39. The villagers told the stranded tourist that the only $<$ VEHICLE, HOPE > [for getting him home] was a $<$ TRUCK, WAGON > which was used for carrying hay

40. She was determined to stop him with the only <WEAPON, THING > she had [in the house], the <PISTOL, POISON $>$ she had hidden in her purse.

\section{APPENDIX B \\ Stimulus Sentences from Experiment 2}

1. Although the <ATTORNEYS, EXECUTIVES, PEOPLE $>$ seemed to understand, < the LAWS > on chemical dumping were read to them to emphasize our position.

Although the <ATTORNEYS, EXECUTIVES, PEOPLE $>$ seemed to understand < the LAWS $>$ on chemical dumping, we read them to emphasize our position.

We asked everyone in the auditorium to be silent. < The LAWS $>$ on chemical dumping were read to the audience to emphasize our position.

2. Although the <AUTHOR, ECONOMIST, GUY> had wanted to finish, < the BOOK > about the economic crisis was rushed into publication in rough form.

Although the <AUTHOR, ECONOMIST, GUY> had wanted to finish < the BOOK > about the economic crisis, speaking engagements took all of his time.

The company believed their timing was perfect. < The $\mathrm{BOOK}>$ on the economic crisis was rushed into publication.

3. I ate the <BREAD, RICE, STUFF $>$, and $<$ the BUTTER $>$ from the refrigerator made it seem less stale.

I ate the $<$ BREAD, RICE, STUFF $>$ and <the BUTTER $>$ from the refrigerator, but I was still hungry.

I had a snack. < The BUTTER > from the refrigerator made it seem less stale.

4. The singer introduced his (the) $<$ BROTHER, MANAGER, FELLOW > and < his SISTER > in the audience applauded loudly.

The singer introduced his (the) $<$ BROTHER, MANAGER, FELLOW > and < his SISTER > in the audience, and they were warmly applauded.

The singer finished his performance. < His SISTER > in the audience applauded loudly.

5. I picked up the <BRUSH, TOOTHBRUSH, THING $>$, and $<$ the COMB $>$ on the sink fell into the toilet.

I picked up the <BRUSH, TOOTHBRUSH, THING $>$ and $<$ the COMB > on the sink, then I put them into my bag. I turned around quickly. <The COMB $>$ on the sink was knocked into the toilet.

6. I called the <CAT, PONY, THING > and < the DOGS $>$ from across the street came running into the yard.

I called the <CAT, PONY, THING > and < the DOGS $>$ from across the street, but they refused to come back.

I opened the door. < The DOGS> from across the street rushed into the kitchen.

7. Once the <COOK, HELPER, GUY > had washed, < the FOOD $>$ for the banquet was brought to him.

Once the <COOK, HELPER, GUY > had washed < the FOOD $>$ for the banquet, he began to prepare it.

It was time to get ready. < The FOOD > for the banquet was brought to the cook.

8. When the <COW, PIG, THING > kicked, < the MILK > in the bucket spilled all over the farmer.

When the <COW, PIG, THING > kicked < the MILK> in the bucket, it spilled all over the farmer.

The man tripped. < The MILK > in the bucket spilled all over the farmer. 


\section{APPENDIX B (Continued)}

9. When the <CUP, JAR, THING > hit, < the SAUCER > in the sink was broken.

When the <CUP, JAR, THING > hit < the SAUCER> in the sink, both of them broke.

My hand was slippery. < The SAUCER > in the sink broke when I dropped the plate on it.

10. He shot the $<$ DECOY, SIGN, OBJECT $>$, and $<$ the DUCK $>$ in the pond escaped without a scratch.

He shot the <DECOY, SIGN, OBJECT $>$ and $<$ the DUCK $>$ in the pond, but the water was too murky to recover either.

I was pleased. <The DUCK > in the pond escaped the hunter.

11. However gently the <DENTIST, TECHNICIAN, FELLOW $>$ explored, <the TOOTH $>$ with the cavity felt like it was being jabbed.

However gently the <DENTIST, TECHNICIAN, FELLOW > explored < the TOOTH > with the cavity, it felt like it was being jabbed.

The fellow sat stiffly in the chair. < The TOOTH > with the cavity felt like it was being jabbed.

12. I called the <DETECTIVE, CORONER, FELLOW $>$, and $<$ the POLICE $>$ from headquarters arrived with him.

I called the <DETECTIVE, CORONOR, FELLOW $>$ and $<$ the POLICE $>$ from headquarters, but they seemed uninterested in what I had found.

I made an urgent phone call. < The POLICE $>$ from headquarters arrived quickly.

13. When the <DOCK, TRAILER, OBJECT $>$ overturned, $<$ the BOATS $>$ of the club members were damaged.

When the <DOCK, TRAILER, OBJECT $>$ overturned $<$ the BOATS $>$ of the club members, the careless manager was fired.

The manager had been negligent. < The BOATS $>$ of the club members were damaged in the storm.

14. I called for the <DOCTOR, SURGEON, MAN>, and $<$ the NURSE $>$ behind the desk came running into the room.

I called for the <DOCTOR, SURGEON, MAN $>$ and $<$ the NURSE $>$ behind the desk, and they came running into the room.

The buzzer made a loud noise. < The NURSE $>$ behind the desk came running into the room.

15. The renters damaged the <DOORS, FURNACE, OBJECT $>$, and $<$ the WINDOWS $>$ in the old house were broken also.

The renters damaged the <DOORS, FURNACE, OBJECT > and <the WINDOWS > in the old house, so the landlord was pretty angry.

We stopped the rowdy party too late. <The WINDOWS> in the new house were already broken.

16. The politician denounced several <ENEMIES, ADVISORS, PEOPLE > and < his FRIENDS > at the convention seemed uncomfortable with the tone of his speech.
The politician denounced several <ENEMIES, ADVISORS, PEOPLE > and < his FRIENDS > at the convention, saying that his campaign had been unfairly criticized. The politician gave a long speech. < His FRIENDS > at the convention seemed a bit uncomfortable.

17. The student saw her (the) <FATHER, FRIEND, MAN >, and $<$ her MOTHER $>$ in the car watched them embrace. The student saw her (the) <FATHER, FRIEND, MAN > and $<$ her MOTHER $>$ in the car, and ran over to greet them.

The student was with her friend. < Her MOTHER > in the car watched them embrace.

18. Because the <HAMMER, PLIERS, THING $>$ had broken, $<$ the NAILS $>$ in the plank were impossible to remove.

Because the <HAMMER, PLIERS, THING > had broken $<$ the NAILS > in the plank, walking barefoot was dangerous.

We tried everything we could think of. < The NAILS > in the plank were impossible to remove.

19. She hung up her $<$ HAT, BAG, THING $>$, and $<$ the COAT $>$ on the hook fell onto the floor.

She hung up her $<$ HAT, BAG, THING $>$ and $<$ the COAT $>$ on the hook, then she turned to speak with us. I opened the door. <The COAT > on the hook fell onto the floor.

20. Although the <HUMP, SADDLE, THING $>$ made it hard to stay on, < the CAMEL > with the nasty disposition was not fun to ride.

Although the <HUMP, SADDLE, THING $>$ made it hard to stay on < the CAMEL > with the nasty disposition, riding it was not fun.

I did not enjoy myself very much at the circus. < The CAMEL $>$ with the nasty disposition bit me.

21. Because the <JEWELER, PRODUCER, MAN > remembered, $<$ the DIAMOND $>$ of the actress was delivered to her room.

Because the <JEWELER, PRODUCER, MAN > remembered < the DIAMOND> of the actress, it was delivered to her room.

It was time for her to leave. <The DIAMOND> of the actress was delivered to her room.

22. Mr. Jones addressed the <JURY, CROWD, PEOPLE >, and < the JUDGE > in the murder trial listened intently. Mr. Jones addressed the <JURY, CROWD, PEOPLE > and <the JUDGE > in the murder trial, while everyone listened intently.

The speech was delivered with great passion. <The JUDGE $>$ in the murder trial listened intently.

23. The guard saluted the <KING, AMBASSADOR, MAN >, and < the QUEEN> in the carriage looked annoyed.

The guard saluted the <KING, AMBASSADOR, MAN > and < the QUEEN > in the carriage, but they didn't notice. The crowd jeered loudly. < The QUEEN > in the carriage looked annoyed.

24. When the <LEAVES, SNOW, STUFF $>$ blew off, < the TREES $>$ in the backyard seemed very bare. 


\section{APPENDIX B (Continued)}

When the <LEAVES, SNOW, STUFF $>$ blew off $<$ the TREES $>$ in the backyard, the area seemed very bleak.

Winter had arrived. < The TREES > in the backyard looked very bleak.

25. Although the <LION, DOG, THING > attacked, <the TIGER $>$ on the steel chain was able to defend itself.

Although the <LION, DOG, THING > attacked <the TIGER $>$ on the steel chain, the trainer was able to stop the fight.

We were glad the fence was high. $<$ The TIGER $>$ on the steel chain seemed huge.

26. Sometime after the <MECHANIC, WATCHMAN, FELLOW > left, <the CARS > in the parking lot were vandalized.

Sometime after the $<$ MECHANIC, WATCHMAN, FELLOW > left <the CARS > in the parking lot, they were vandalized.

Everyone was very angry and upset. < The CARS > in the parking lot had been vandalized.

27. After the <MILLIONAIRE, CLERK, FELLOW > had finished counting, <the MONEY > in the green envelopes was returned to the safe.

After the <MILLIONAIRE, CLERK, FELLOW> had finished counting < the MONEY> in the green envelopes, it was returned to the safe.

We were satisfied that all care had been taken. < The MONEY > in the green envelopes was returned to the safe.

28. I knew the <MONK, SPEAKER, MAN>, and <the PRIEST $>$ at the convention looked familiar too.

I knew the <MONK, SPEAKER, MAN> and <the PRIEST $>$ at the convention, but they didn't recognize me. I waved my hand. < The PRIEST $>$ in the room recognized me.

29. When the <MUG, CAN, THING > leaked, <the BEER> on the floor had to be cleaned up.

When the <MUG, CAN, THING > leaked < the BEER > on the floor, we had to clean up the mess.

The party was over. < The BEER > on the floor had to be cleaned up.

30. As his (the) <PIANO, TAPE RECORDER, OBJECT > revealed, < the MUSIC > of the young composer had power and depth.

As his (the) <PIANO, TAPE RECORDER, OBJECT > revealed < the MUSIC > of the young composer, we were astounded by the music's power and depth.

We were astounded. < The MUSIC> of the young composer had such power and depth.

31. Although the <PILOT, CAPTAIN, FELLOW > was unable to brake, < the PLANE > on the icy runway rolled to a stop.

Although the <PILOT, CAPTAIN, FELLOW $>$ was unable to brake < the PLANE > on the icy runway, it rolled to a stop.

Everyone breathed a sign of relief. < The PLANE > on the icy runway rolled to a stop.
32. They found the <PISTOL, KNIFE, OBJECT $>$, and < the BULLETS $>$ in the box nearby were the same as those used in the robbery.

They found the $<$ PISTOL, KNIFE, OBJECT $>$ and $<$ the BULLETS $>$ in the box nearby were the same as those used in the robbery.

It was just as we had suspected. < The BULLETS > in the box were the same as those used in the robbery.

33. Although the <PLUMBER, REPAIRMAN, MAN $>$ had left, <the PIPES > in the basement were still leaking.

Although the $<$ PLUMBER, REPAIRMAN, MAN $>$ had left $<$ the PIPES $>$ in the basement, the kitchen was still cluttered.

We were not very happy about the repairs. <The PIPES > in the basement were still leaking.

34. The new tax hurt the <POOR, WORKERS, PEOPLE $>$, and $<$ the RICH $>$ from the city benefited.

The new tax hurt the $<$ POOR, WORKERS, PEOPLE $>$ and <the RICH > from the city to an equal degree.

It was the same old story. < The RICH $>$ from the city benefited from the tax.

35. The explosion startled the <RIDER, TOURIST, GUY >, and < the HORSE > with the supplies got loose.

The explosion startled the <RIDER, TOURIST, GUY > and $<$ the HORSE > with the supplies, but there were no injuries.

The explosion caused great chaos. < The HORSE > with the supplies got loose.

36. He bumped the <SALT, FLOUR, STUFF > and <the PEPPER $>$ in the nearby containers was knocked into the stew.

He bumped the <SALT, FLOUR, STUFF > and < the PEPPER $>$ in the nearby container, and they fell into the stew.

I was not paying attention. < The PEPPER > in the open containers fell into the stew.

37. Although the $<$ SHOE, BANDAGE, THING $>$ hurt, $<$ the FOOT $>$ with the blisters was protected by it.

Although the $<$ SHOE, BANDAGE, THING $>$ hurt $<$ the FOOT $>$ with the blisters, John thought it was wise to keep it on.

He was not worried. < The FOOT > with the blisters was protected by a bandage.

38. Because the <SOLDIERS, GUARDS, PEOPLE $>$ refused to leave, < the ARMY > of the dictator executed them.

Because the <SOLDIERS, GUARDS, PEOPLE $>$ refused to leave $<$ the ARMY > of the dictator, the rebels executed them.

The situation was getting worse. <The ARMY > of the dictator executed some rebels.

39. He found the <SPOOL, PATCH, THING $>$, and $<$ the THREAD $>$ in the basket was just the right color.

He found the <SPOOL, PATCH, THING $>$ and $<$ the THREAD > in the basket, so he was able to repair the rip quickly.

I was surprised. < The THREAD > in the basket was just the right color. 


\section{APPENDIX B (Continued)}

40. I removed the $<$ TABLE, TRUNK, THING $>$, and $<$ the CHAIRS $>$ from the attic finally fit into the room.

I removed the $<$ TABLE, TRUNK, THING $>$ and $<$ the CHAIRS > from the attic, so the place seemed less cluttered. I was very pleased. $<$ The CHAIRS $>$ from the attic fit into the room easily.

41. We liked the <TEACHERS, STAFF, PEOPLE > and $<$ the SCHOOL > in the little town seemed progressive, but we enrolled our children elsewhere.

We liked the <TEACHERS, STAFF, PEOPLE $>$ and $<$ the SCHOOL $>$ in the little town, but we decided to enroll our children elsewhere.
It was not an easy decision. < The SCHOOL > in the little town seemed progressive, but we enrolled our children elsewhere.

42. Because the <WEB, LACE, THING $>$ shook, <the SPIDER $>$ with the funny legs left for a safer place.

Because the <WEB, LACE, THING > shook < the SPIDER > with the funny legs, it left for a safer place. Mary refused to kill a living thing. < The SPIDER $>$ with the funny legs ran away.

(Manuscript received September 20, 1985; revision accepted for publication April 16, 1986.) 